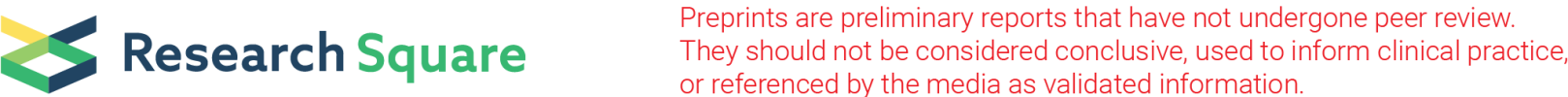

\section{Acute pancreatitis following treatment with protease inhibitors, which may be potential therapeutics for COVID-19: A real-world analysis of postmarketing surveillance data}

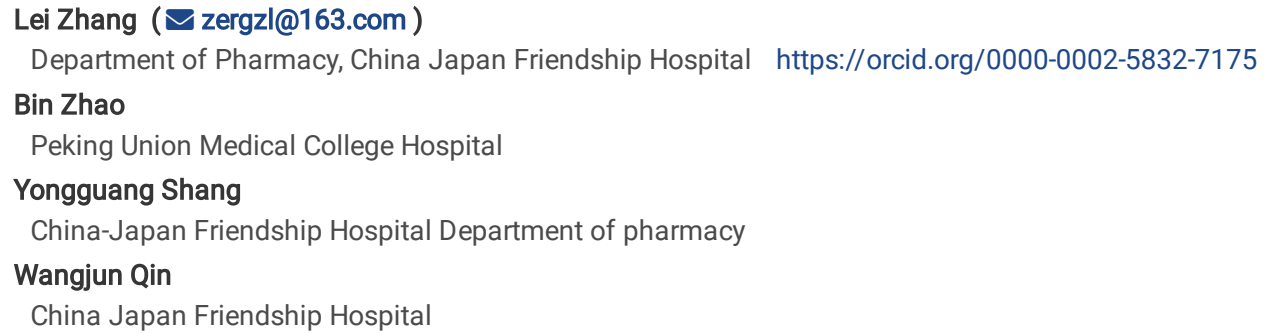

Research article

Keywords: Protease inhibitors, Acute pancreatitis, Adverse drug events, COVID-19, Spontaneous reporting system, Data mining, Medication safety, riskmanagement

Posted Date: June 9th, 2020

DOI: https://doi.org/10.21203/rs.3.rs-31947/v1

License: (c) (7) This work is licensed under a Creative Commons Attribution 4.0 International License. Read Full License 


\section{Abstract}

Backgrounds: The potential therapeutic effects of protease inhibitors (PIs), such as lopinavir/ritonavir and darunavir, on COVID-19 are being tested in clinical trials. Although acute pancreatitis (AP) has been reported in patients treated with Pls, there have been few real-world studies comparing the occurrence and characteristics of AP after different PI regimens.

Methods: Disproportionality analysis and Bayesian analysis were utilized for data mining of the Food and Drug Administration's Adverse Event Reporting System (FAERS) database for suspected adverse events involving AP after PI from January 2004 to December 2019. The times to onset and fatality rates of AP following different PI regimens were also compared.

Results: Based on 33,832 reports related to PIs, 285 cases ( $0.84 \%$ of total adverse drug reactions, ADRs) were associated with AP; in these reports, the number of AP cases reported for the top five Pls was as follows: ritonavir/dasabuvir/ombitasvir/paritaprevir, 64 (22.46\%); ritonavir, 54 (18.95\%); atazanavir, 52 (18.25\%); lopinavir/ritonavir, 48 (16.84\%); and darunavir, 26 (9.12\%). Twelve out of the 15 studied Pls, including lopinavir/ritonavir, darunavir and nelfinavir, which are potential therapeutics for COVID-19, were associated with AP. Of all the reported adverse events involving AP related to PIs, $64.56 \%$ occurred in men, which was a much higher proportion than what was observed in women (28.42\%). The median time to onset of AP was 103 (IQR: 26-408) days after the initiation of PI treatment. Patients treated with ritonavir/dasabuvir/ombitasvir/paritaprevir appeared to have an earlier onset of AP than those receiving atazanavir (31 [IQR: 17-68.25] days vs 187.5 [IQR: 80.5-556.5] days, p=0.0379) or ritonavir (31 [IQR: 17-68.25] days vs 177 [IQR: $56-539$ ] days, p=0.0371). Compared with AP cases induced by all studied Pls, which had a fatality rate of $14.02 \%$, AP cases associated with ritonavir (18.87\%) and lopinavir/ritonavir (22.73\%) appeared to be associated with a higher risk of death.

Conclusions: Analysis of the FAERS data provides a more precise understanding of the occurrence and characteristics of AP after different PI regimens. Signals for AP associated with various PI regimens have been detected. The findings support continued surveillance, risk factor identification, and comparative studies.

\section{Declarations}

Ethics approval and consent to participate As this was an observational and retrospective study, and the database is open to the public, this study was exempt from approval by China Japan Friendship Hospital Institutional Review Board.

Consent for publication Not applicable

Availability of data and material All adverse event reports extracted during the current study are available in the FDA's Adverse Event Reporting System (FAERS) database [https://fis.fda.gov/extensions/FPD-QDE-FAERS/FPD-QDE-FAERS.html]. And all data generated and analyzed during the study has been presented in the tables and figures. Other related information is available under request to the corresponding author.

Competing interest The authors declare that they have no competing interests that are directly relevant to the content of this study.

Funding This research did not receive any specific grant from funding agencies in the public, commercial, or not-for-profit sectors.

Authors' contributions Lei Zhang designed the research, analyzed and interpreted data, wrote the manuscript draft, and corrected it. Bin Zhao designed the research, participated in the interpretation of data, and corrected the manuscript. Yongguang Shang participated in the interpretation of data and writing of the manuscript draft. Wangjun Qin participated in the study design, plotted figures, and collected data.

Acknowledgements We thank all participants of the study.

\section{Introduction}

As of May 24, 2020, coronavirus disease 2019 (COVID-19), which is caused by a novel coronavirus (named SARS-CoV-2 by WHO) and was first identified in Wuhan, China, has spread globally. The number of globally confirmed cases is more than 5204,000 as of the submission of this manuscript ${ }^{[1]}$. To date, there are no specific treatments for COVID-19. Identifying effective and safe drugs to treat the virus as soon as possible is critical for the response to the COVID-19 outbreak.

The combination of lopinavir and ritonavir is widely used as a pharmacologically boosted protease inhibitor (PI) in highly active antiretroviral therapy (HAART) for human immunodeficiency virus (HIV)-infected patients ${ }^{[2,3]}$. Due to its demonstrated efficacy in treating pneumonia associated with severe acute respiratory syndrome coronavirus (SARS-CoV) ${ }^{[4]}$ and Middle East respiratory syndrome coronavirus (MERS-CoV) ${ }^{[5,6]}$ in addition to its activity against SARSCoV-2 in vitro, lopinavir/ritonavir has been applied to treat COVID-19, and some cases have been reported ${ }^{[7,8]}$. Triple combination therapy with ritonavir/lopinavir, ribavirin and interferon-alpha has been recommended as a drug treatment option by the guidelines for the diagnosis and treatment of COVID-19 (trial version 7), which was published by the National Health Commission of China. Nelfinavir, another PI that can strongly inhibit the replication of SARS-CoV ${ }^{[9]}$, may also be a candidate drug for COVID-19.

In the absence of a specific treatment for COVID-19, several subsequent clinical trials (ChiCTR2000030187, ChiCTR2000029741, ChiCTR2000029603, ChiCTR2000029573, ChiCTR2000029548, ChiCTR2000029541, ChiCTR2000029539, ChiCTR2000029468, ChiCTR2000029387, and ChiCTR2000029308) have been quickly conducted in China to test the efficacy and safety of lopinavir/ritonavir and darunavir/cobicistat (another boosted $\mathrm{PI}$ ) as monotherapies or 
combination therapies for the treatment of COVID-19-associated pneumonia in more than 10 hospitals ${ }^{[10]}$. Under this circumstance, not only the efficacy but also the safety of these PIs for the treatment of COVID-19 still need to be further confirmed.

As part of HAART, PIs have led to a significant decline in HIV-related morbidity and mortality ${ }^{[11]}$. However, PI-based treatments are, in general, associated with changes in the distribution of body fat and metabolic disorders, such as insulin resistance, hypercholesterolemia, and hypertriglyceridemia ${ }^{[12-15]}$. The latter is usually severe and difficult to control and may trigger episodes of $\mathrm{AP}^{[16]}$. Pl-associated pancreatitis, some cases of which were fatal, has been observed ${ }^{[17,18]}$. The risk of severe pancreatitis induced by PI therapy has attracted a great deal of attention. Previous studies have evaluated whether the etiology of AP has changed since PI-based HAART therapy was first introduced in 1996 ${ }^{[19-22]}$. However, past studies have reported conflicting results regarding the impact of PIs on the development of pancreatitis ${ }^{[16]}$. Moreover, most evidence supporting the causal relationship between AP and PIs has come from case reports ${ }^{[23-25]}$ and is insufficient to provide an overview of the risk of rare adverse events such as AP.

Pharmacovigilance studies regarding Pl-induced AP events are still scarce. In particular, we still know little about the safety profile of PI regimens in regard to pancreatitis in clinical practice. Characterizing Pl-associated pancreatitis may provide important clues for patient safety during antiviral therapy. By analyzing adverse events extracted from the FDA's Adverse Event Reporting System (FAERS) database, we focused on evaluating and comparing the associations between various $\mathrm{PI}$ regimens and $\mathrm{AP}$ in a large real-world patient population. In addition, we investigated fatality rates and the times to onset of $\mathrm{AP}$ after the administration of various $\mathrm{PI}$ regimens.

\section{Materials And Methods}

\subsection{Data source}

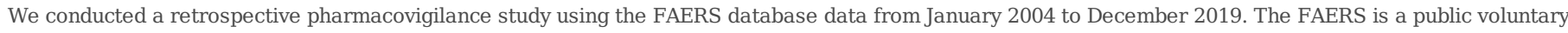
spontaneous reporting database that provides information on adverse event and medication error reports submitted by health professionals, consumers, and manufacturers both domestically and abroad.

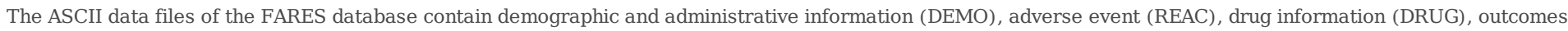
(OUTC), report sources (RPSR), therapy information (THER) and using indications (INDI).

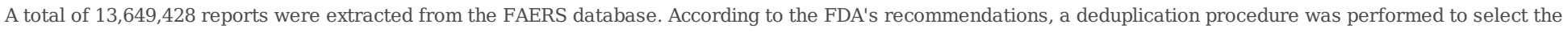

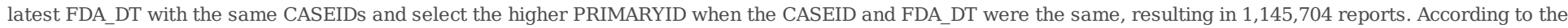
PRIMARYID of the deduplicated DEMO data, the DRUG and REAC data were deduplicated as well.

\subsection{Adverse event and drug identification}

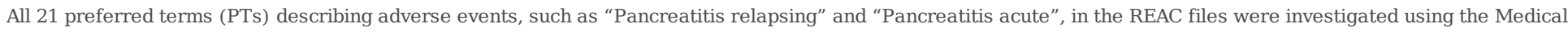
Dictionary for Regulatory Activities(MedDRA) V23.0 and the Standardised MedDRA Queries (SMQ) term “acute pancreatitis" (SMQ: 20000022).

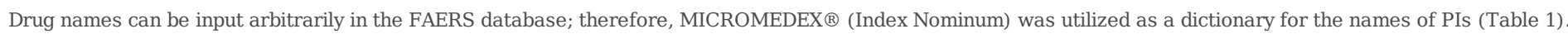
Both generic names and brand names were used as keywords for FAERS database retrieval.

Table 1: Summary of FDA-approved protease inhibitors 


\begin{tabular}{|c|c|c|}
\hline Generic name & Brand name & Approval year \\
\hline Atazanavir & Reyataz $^{\circledR}$ & 2003 \\
\hline Atazanavir/cobicistat & Evotaz ${ }^{\circledR}$ & 2015 \\
\hline Amprenavir & Agenerase ${ }^{\circledR}$ & 1999 \\
\hline Fosamprenavir & Lexiva ${ }^{\circledR}$, Telzir $^{\circledR}$ & 2003 \\
\hline Nelfinavir & Viracept ${ }^{\circledR}$ & 1997 \\
\hline Saquinavir & Fortovase ${ }^{\circledR}$, Invirase ${ }^{\circledR}$ & 1995 \\
\hline Tipranavir & Aptivus ${ }^{\circledR}$ & 2005 \\
\hline Indinavir & Crixivan ${ }^{\circledR}$ & 1996 \\
\hline Darunavir & Prezista ${ }^{\circledR}$ & 2007 \\
\hline Darunavir/cobicistat & Rezolsta ${ }^{\circledR}$, Prezcobix ${ }^{\circledR}$ & 2014 \\
\hline Darunavir/cobicistat/emtricitabine/tenofovir & Symtuza ${ }^{\circledR}$ & 2018 \\
\hline Ritonavir & Norvir ${ }^{\circledR}$ & 1996 \\
\hline Ritonavir/lopinavir & Kaletra ${ }^{\circledR}$ & 2001 \\
\hline Ritonavir/dasabuvir/ombitasvir/paritaprevir & Holkira ${ }^{\circledR}$, Viekira ${ }^{\circledR}$ & 2014 \\
\hline Ritonavir/ombitasvir/paritaprevir & Technivie $^{\circledR}$ & 2015 \\
\hline
\end{tabular}

\subsection{Data mining}

The disproportionality analysis (the reporting odds ratio, ROR and the proportional reporting ratio, PRR) and the Bayesian analysis (the Bayesian confidence

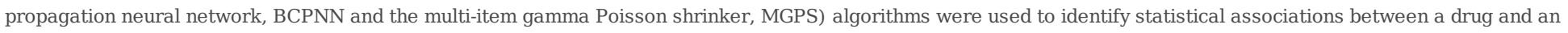
adverse event (Table 2) ${ }^{[26-34]}$. In this study, adverse events were extracted when at least 1 of 4 indices met the criteria.

\section{Table 2: Summary of Major Algorithms Used for Signal Detection}

\begin{tabular}{|c|c|c|}
\hline Algorithm & Equation & Criteria \\
\hline \multirow[t]{2}{*}{ ROR } & $\mathrm{ROR}=(\mathrm{a} / \mathrm{b}) /(\mathrm{c} / \mathrm{d})$ & $95 \% \mathrm{CI}>1, \mathrm{~N} \geq 2$ \\
\hline & $95 \% \mathrm{CI}=\mathrm{e}^{\ln (\mathrm{ROR}) \pm 1.96(1 / \mathrm{a}+1 / \mathrm{b}+1 / \mathrm{c}+1 / \mathrm{d}) \wedge 0.5}$ & \\
\hline \multirow[t]{2}{*}{ PRR } & $\mathrm{PRR}=(\mathrm{a} /(\mathrm{a}+\mathrm{c})) /(\mathrm{b} /(\mathrm{b}+\mathrm{d}))$ & $\mathrm{PRR} \geq 2, \chi^{2} \geq 4, \mathrm{~N} \geq 3$ \\
\hline & $\chi 2=\Sigma((\mathrm{O}-\mathrm{E}) 2 / \mathrm{E}) ;(\mathrm{O}=\mathrm{a}, \mathrm{E}=(\mathrm{a}+\mathrm{b})(\mathrm{a}+\mathrm{c}) /(\mathrm{a}+\mathrm{b}+\mathrm{c}+\mathrm{d}))$ & \\
\hline \multirow[t]{2}{*}{ BCPNN } & $\mathrm{IC}=\log _{2} \mathrm{a}(\mathrm{a}+\mathrm{b}+\mathrm{c}+\mathrm{d}) /((\mathrm{a}+\mathrm{c})(\mathrm{a}+\mathrm{b}))$ & IC $025>0$ \\
\hline & $\operatorname{IC} 025=\mathrm{e}^{\ln (\mathrm{IC})-1.96(1 / \mathrm{a}+1 / \mathrm{b}+1 / \mathrm{c}+1 / \mathrm{d}) \wedge 0.5}$ & \\
\hline \multirow[t]{2}{*}{ MGPS } & $\mathrm{EBGM}=\mathrm{a}(\mathrm{a}+\mathrm{b}+\mathrm{c}+\mathrm{d}) /((\mathrm{a}+\mathrm{c})(\mathrm{a}+\mathrm{b}))$ & EBGM05>2, N>0 \\
\hline & EBGM05 $=\mathrm{e}^{\ln (\mathrm{EBGM})-1.64(1 / \mathrm{a}+1 / \mathrm{b}+1 / \mathrm{c}+1 / \mathrm{d}) \wedge 0.5}$ & \\
\hline
\end{tabular}

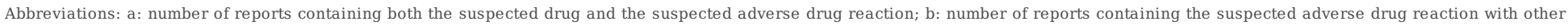

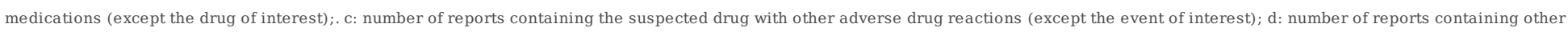

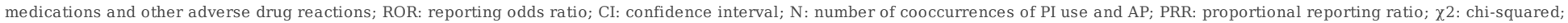

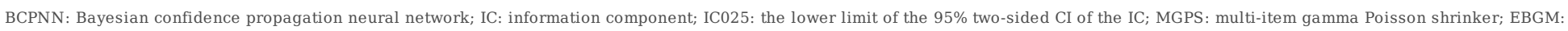
empirical Bayesian geometric mean; EBGM05: the lower 90\% one-sided CI of EBGM 


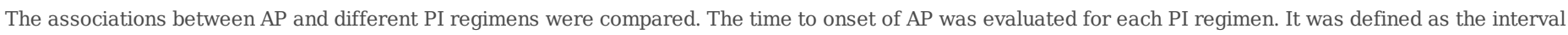

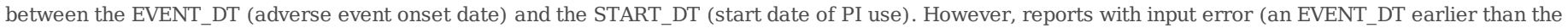

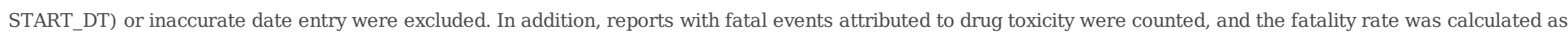
the number of fatal events divided by the total number of events of AP associated with each PI regimen.

\subsection{Statistical analysis}

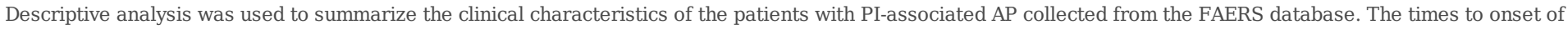

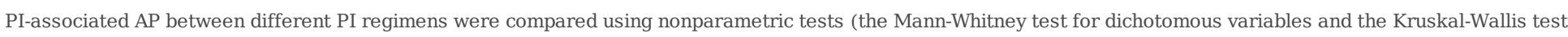

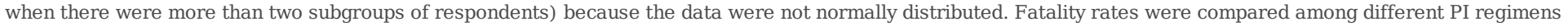

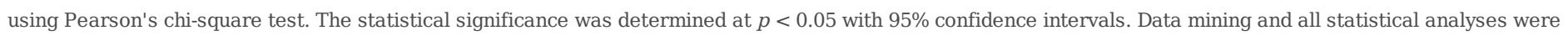
performed with SAS, version 9.4 (SAS Institute Inc., Cary, NC, USA).

\section{Results}

\subsection{Descriptive analysis}

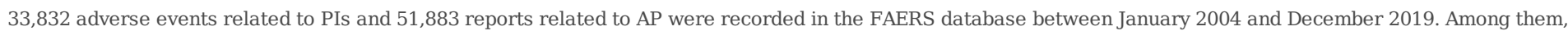
PIs were set as the suspected drugs that caused AP in 285 reports, and the clinical characteristics of these patients are presented in Table 3.

Table 3: Clinical characteristics of patients with protease inhibitor-associated acute pancreatitis collected from the FAERS database 


\begin{tabular}{|c|c|}
\hline Characteristics & Reports, no. (\%) \\
\hline \multicolumn{2}{|l|}{ Reporting region } \\
\hline North America & $115(40.35)$ \\
\hline Europe & $88(30.88)$ \\
\hline Asian & $19(6.67)$ \\
\hline Oceania & $9(3.16)$ \\
\hline South America & $4(1.4)$ \\
\hline Africa & $1(0.35)$ \\
\hline Unknown or missing & 49 (17.19) \\
\hline \multicolumn{2}{|l|}{ Reporters } \\
\hline Health-care professional & 205 (71.93) \\
\hline Non-health-care professional & $42(14.74)$ \\
\hline Unknown or missing & $38(13.33)$ \\
\hline \multicolumn{2}{|l|}{ Reporting year } \\
\hline 2001-2005 & $58(20.35)$ \\
\hline $2006-2010$ & $87(30.53)$ \\
\hline 2011-2015 & $65(22.81)$ \\
\hline 2016-2019 & $74(25.96)$ \\
\hline Unknown or missing & $1(0.35)$ \\
\hline \multicolumn{2}{|l|}{ Patient gender } \\
\hline Male & $184(64.56)$ \\
\hline Female & $81(28.42)$ \\
\hline Unknown or missing & $20(7.02)$ \\
\hline \multicolumn{2}{|l|}{ Patient age group (years) } \\
\hline$<18$ & $2(0.70)$ \\
\hline $18-44$ & $71(24.91)$ \\
\hline $45-64$ & $80(28.07)$ \\
\hline$>64$ & $34(11.93)$ \\
\hline Unknown or missing & $98(34.39)$ \\
\hline \multicolumn{2}{|l|}{ Suspected PI drug } \\
\hline Atazanavir & $52(18.25)$ \\
\hline Atazanavir/cobicistat & $(0)$ \\
\hline Amprenavir & $2(0.7)$ \\
\hline Fosamprenavir & $10(3.51)$ \\
\hline Nelfinavir & $5(1.75)$ \\
\hline Saquinavir & $4(1.4)$ \\
\hline Tipranavir & $7(2.46)$ \\
\hline Indinavir & $8(2.81)$ \\
\hline Darunavir & $26(9.12)$ \\
\hline Darunavir/cobicistat & $2(0.7)$ \\
\hline Darunavir/cobicistat/emtricitabine/tenofovir & $1(0.35)$ \\
\hline Ritonavir & $54(18.95)$ \\
\hline Ritonavir/lopinavir & $48(16.84)$ \\
\hline Ritonavir/dasabuvir/ombitasvir/paritaprevir & $64(22.46)$ \\
\hline
\end{tabular}




\begin{tabular}{ll}
\multicolumn{1}{c}{ Ritonavir/ombitasvir/paritaprevir } & $2(0.7)$ \\
\hline Indications & \\
\hline HIV infection & $171(64.77)$ \\
\hline Hepatitis C and hepatic cirrhosis & $66(25)$ \\
\hline Unknown or missing & $27(10.23)$ \\
\hline
\end{tabular}

Data are number (\%). PI: protease inhibitor; FAERS: Food and Drug Administration's Adverse Event Reporting System

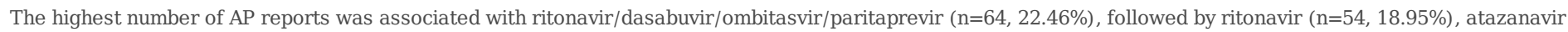

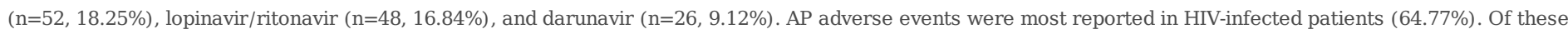

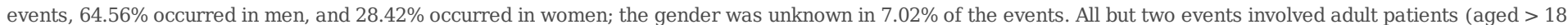

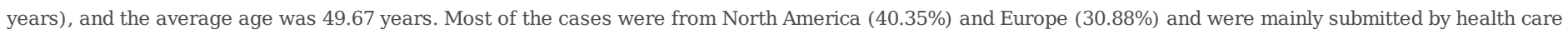
professionals (71.93\%).

\subsection{Disproportionality analysis and Bayesian analysis}

No cooccurrence of atazanavir/cobicistat use and AP was reported, and only 1 and 2 cooccurrences of PI use and AP were reported for

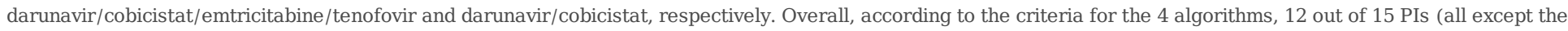

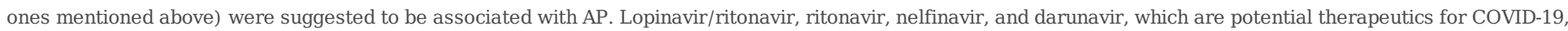

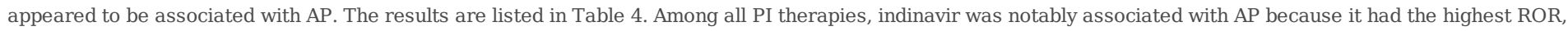
PRR, IC, and EBGM.

Table 4: Disproportionality analysis and the Bayesian analysis of associations of different protease inhibitor regimens with acute pancreatitis

\begin{tabular}{|c|c|c|c|c|c|}
\hline PI regimens & $\mathrm{N}$ & $\begin{array}{l}\text { ROR } \\
\text { (95\% two-sided CI) }\end{array}$ & $\begin{array}{l}\text { PRR } \\
\left(\chi^{2}\right)\end{array}$ & $\begin{array}{l}\text { IC } \\
\text { (95\% one-side CI) }\end{array}$ & $\begin{array}{l}\text { EBGM } \\
\text { ( } 95 \% \text { one-side CI) }\end{array}$ \\
\hline Atazanavir & 52 & $3.01(2.29,3.96)$ & $2.99(68.9)$ & $1.58(1.2)$ & $2.98(2.37)$ \\
\hline Atazanavir/cobicistat & 0 & - & - & - & - \\
\hline Amprenavir & 2 & $3.89(0.96,15.75)$ & $3.84(4.22)$ & $1.94(0.48)$ & $3.84(1.19)$ \\
\hline Fosamprenavir & 10 & $4.14(2.22,7.74)$ & $4.08(23.38)$ & $2.03(1.09)$ & $4.08(2.42)$ \\
\hline Nelfinavir & 5 & $1.97(0.82,4.75)$ & $1.96(2.37)$ & $0.97(0.4)$ & $1.96(0.94)$ \\
\hline Saquinavir & 4 & $2.26(0.84,6.05)$ & $2.25(2.78)$ & $1.17(0.44)$ & $2.25(0.99)$ \\
\hline Tipranavir & 7 & $2.66(1.26,5.6)$ & $2.64(7.15)$ & $1.4(0.66)$ & $2.64(1.41)$ \\
\hline Indinavir & 8 & $4.6(2.29,9.27)$ & $4.53(22.11)$ & $2.18(1.08)$ & $4.53(2.52)$ \\
\hline Darunavir & 26 & $2.08(1.41,3.06)$ & $2.07(14.37)$ & $1.05(0.71)$ & $2.07(1.5)$ \\
\hline Darunavir/cobicistat & 2 & $0.76(0.19,3.05)$ & $0.76(0.15)$ & $-0.39(-)$ & $0.76(0.24)$ \\
\hline Darunavir/cobicistat/emtricitabine/teno fovir & 1 & $0.98(0.14,6.97)$ & $0.98(0)$ & $-0.03(-)$ & $0.98(0.19)$ \\
\hline Ritonavir & 54 & $2.07(1.58,2.71)$ & $2.06(29.61)$ & $1.04(0.8)$ & $2.06(1.65)$ \\
\hline Ritonavir/lopinavir & 48 & $2.19(1.65,2.92)$ & $2.18(30.87)$ & $1.13(0.85)$ & $2.18(1.72)$ \\
\hline Ritonavir/dasabuvir/ombitasvir/paritaprevir & 64 & $1.1(0.86,1.41)$ & $1.1(0.56)$ & $0.14(0.11)$ & $1.1(0.89)$ \\
\hline Ritonavir/ombitasvir/paritaprevir & 2 & $2.07(0.52,8.35)$ & $2.06(1.1)$ & $1.05(0.26)$ & $2.06(0.64)$ \\
\hline
\end{tabular}

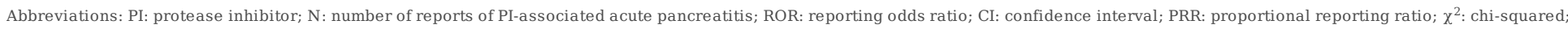
IC: information component; EBGM: empirical Bayes geometric mean 


\subsection{Time to onset of PI-associated AP}

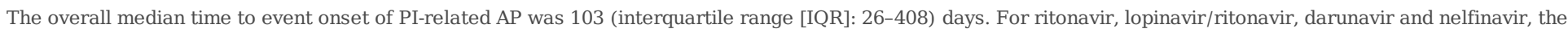

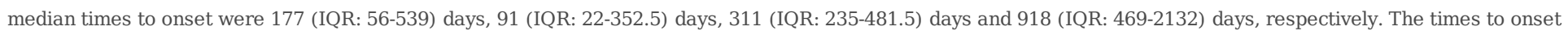
associated with each PI regimen are shown in Fig. 1.

Fig. 1: Time to onset of acute pancreatitis associated with different protease inhibitor regimens (Pearson's chi-square test, $P=0.0048$ )

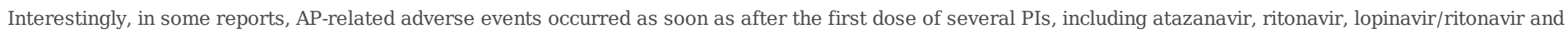

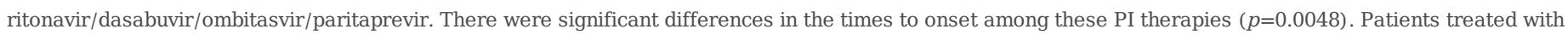

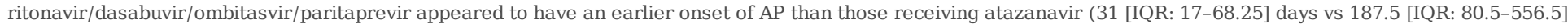
days, $p=0.0379$ ) or ritonavir (31 [IQR: 17-68.25] days vs 177 [IQR: 56-539] days, $p=0.0371$ ).

\subsection{Fatality due to PI-associated AP}

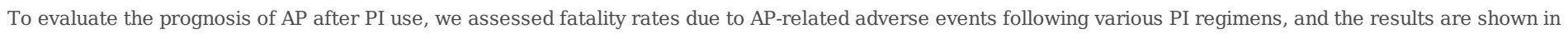

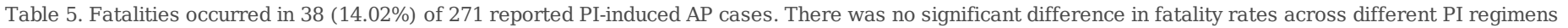
(Pearson's chi-square test for overall comparisons, $p=0.730$ ).

Table 5: Fatality rates due to acute pancreatitis adverse events following various protease inhibitor regimens

\begin{tabular}{|c|c|c|c|}
\hline \multirow[b]{2}{*}{ Atazanavir } & \multicolumn{3}{|c|}{ Death (N) Number of ReportsFatalityl\%[ } \\
\hline & 6 & 52 & 11.54 \\
\hline Atazanavir/cobicistat & - & - & - \\
\hline Amprenavir & 0 & 2 & 0 \\
\hline Fosamprenavir & 0 & 8 & 0 \\
\hline Nelfinavir & 1 & 5 & 20 \\
\hline Saquinavir & 1 & 4 & 25 \\
\hline Tipranavir & 0 & 3 & 0 \\
\hline Indinavir & 1 & 8 & 12.5 \\
\hline Darunavir & 2 & 26 & 7.69 \\
\hline Darunavir/cobicistat & 0 & 2 & 0 \\
\hline Darunavir/cobicistat/emtricitabine/tenofovir & 0 & 1 & 0 \\
\hline Ritonavir & 10 & 53 & 18.87 \\
\hline Ritonavir/lopinavir & 10 & 44 & 22.73 \\
\hline Ritonavir/dasabuvir/ombitasvir/paritaprevir & 6 & 61 & 9.84 \\
\hline Ritonavir/ombitasvir/paritaprevir & 1 & 2 & 50 \\
\hline
\end{tabular}

Data are number or percentage, as appropriate

\section{Discussion}

Since the outbreak of COVID-19, there have been more than 5204,000 confirmed cases globally, and 337,687 people have lost their lives ${ }^{[1]}$. Thousands more are fighting for their lives in hospitals. The World Health Organization (WHO) has characterized COVID-19 as a pandemic. All countries activated and scaled up their emergency response mechanisms, and a great deal of effort has been made to identify effective drugs against the virus. Some PIs, such as lopinavir/ritonavir and darunavir/cobicistat, have been tested in clinical trials in China. This study focused on the occurrence, timing, and prognosis of AP following the use of various PI regimens in real-world practice based on the FAERS pharmacovigilance database. First using disproportionality analysis and 
Bayesian analysis as a rapid and effective signal detection method to perform the largest-to-date postmarketing surveillance of these Pls, we attempted to provide valuable and timely signals for clinical evaluation to minimize the potential harm induced by AP in the treatment of COVID-19. The study showed that 12 out of the 15 studied PIs, including lopinavir/ritonavir, darunavir, and nelfinavir, which are potential therapeutics for COVID-19, were associated with APrelated adverse events.

Despite the potential benefits it provides to COVID-19 patients, the use of PIs may be accompanied by serious side effects, including AP. Two case reports ${ }^{[23,}$ ${ }^{24}$ have suggested a causal mechanism between PI-induced hypertriglyceridemia and AP, while a third case report of PI-associated acute pancreatitis was not associated with a rise in serum triglycerides ${ }^{[25]}$. It remains unclear whether PIs are associated with pancreatitis. Hence, it is important to recognize the associations between particular PI regimens and AP as well as the clinical features and develop an awareness of this adverse event among practitioners prescribing PI for the treatment of COVID-19 and other professionals, such as pharmacists and nurses. However, the assessment of PI-associated AP is quite challenging because of its low incidence and overlooked manifestations ${ }^{[21,22]}$. Due to strict study entry criteria, relatively small sample sizes, and a finite scope and time frame, it is difficult to achieve this goal through experimental studies, including mandatory clinical trials, alone. Performing postmarketing surveillance is an efficient way to discover rare but potentially severe adverse reactions and help us acquire vital basis for prevention. Therefore, our study provides a profile of Pl-associated AP through data mining of 33,832 adverse events related to Pls documented in the FAERS database.

Some prior studies that included patients receiving HAART found an association between female gender and AP and hypothesized that a smaller body weight might increase the toxicity of nucleotide reverse-transcriptase inhibitors (NRTIs) ${ }^{[35,36]}$. However, Manfredi et al. found no association between gender and the risk of AP related to PI-based HAART exposure ${ }^{[21]}$. In our study, based on reports from the FAERS database, we found that PI-associated AP seemed to predominately affect men rather than women (64.56\% vs. $28.42 \%$ ). Most of these collected reports were from North America (40.35\%) and Europe (30.88\%), where women make up a smaller proportion of the HIV patient population ${ }^{[37]}$. Therefore, we could not conclude that men are more likely than women to suffer from AP following PI regimens. Further research is required to reevaluate the relationship between gender and PI-associated AP.

Guo et al. found that advanced age is a risk factor for acute pancreatitis after a retrospective cohort study of 4,972 patients with HIV infection, in which they found 159 cases of $A P^{[38]}$. Conversely, we did not observe that Pl-induced AP predominately affected elderly patients $(11.93 \%$ of patients $\geq 65$ years vs. $53.68 \%$ of patients $<65$ years). On account of a lack of information in the FAERS database, it was difficult to control confounding factors such as age in this study. Further research is needed to explore the association between advanced age and the incidence of PI-related AP.

Previous studies have reported conflicting results regarding the impact of PIs on the development of pancreatitis ${ }^{[16]}$. Most evidence supporting the causal relationship of AP to PIs has come from case reports ${ }^{[23-25]}$ and is insufficient to provide an overview of the risk of rare adverse events such as AP. Riedel et al. found that neither PI nor non-nucleoside reverse-transcriptase inhibitors (NNRTIs) are associated with an increased rate of AP through a ten-year cohort study ${ }^{[39]}$. Conversely, based on this pharmacovigilance analysis, 12 out of the 15 studied PIs were found to be associated with AP-related adverse events, which is similar to what was reported in some prior studies ${ }^{[21,22]}$. Hypertriglyceridemia has been demonstrated to cause pancreatitis ${ }^{[40,41]}$. According to previous studies, all available PIs are associated with significant increases in plasma triglyceride concentrations ${ }^{[42,43]}$, but hypertriglyceridemia is more frequently observed following the use of ritonavir or lopinavir/ritonavir combination therapy than following other Pl-based combinations ${ }^{[44,45]}$. Due to their potential clinicopathological consequences, ritonavir and lopinavir/ritonavir regimens may lead to an increased risk of hyperlipidemic pancreatitis ${ }^{[42,46]}$. Surprisingly, we observed that indinavir, not ritonavir, seemed to have the strongest association with AP among all PI regimens, including ritonavir and lopinavir/ritonavir. This may be due to the relatively limited cases of AP-associated indinavir reported (8 reports). In our study, the $64.77 \%$ of reported cases are involving HIV-infected patients. As we know, antiretroviral treatment is very complex and dangerous due to concomitant medications and their toxic effects, including drug-induced AP. There are plenty of factors which can affect the pancreas, such as a previous history of AP, hepatobiliary diseases, alcohol abuse, low CD 4 counts, and opportunistic infection prophylaxis, in addition to direct lesions caused by HIV ${ }^{[16]}$. All these factors make the evaluation of the association between PI and AP more difficult.

Another finding was that the median time to the onset of AP was 103 (IQR: 26-408) days after the initiation of PI treatment, which was similar to the onset time observed in some previous case reports ${ }^{[23-25]}$. Ritonavir/dasabuvir/ombitasvir/paritaprevir appeared to have the earliest onset of AP (31 [IQR: 17-68.25] days) among all studied PI regimens. For ritonavir and lopinavir/ritonavir, the median times to onset were 177 (IQR: 56-539) days and 91 (IQR: $22-352.5)$ days, respectively. It was suggested that ritonavir-based PI regimens may induce AP earlier than other PI regimens. Although the onset of AP after the use of PI seemed to be long according to some reports collected in this study, AP could occur as soon as after the first several doses of the ritonavir-based PI regimens mentioned above and atazanavir. Notably, triple combination therapy with ritonavir/lopinavir, ribavirin and interferon-alpha has been recommended as a drug treatment option by the guidelines, and it might be predominantly used to treat COVID-19 patients. However, both interferon monotherapy and interferon/ribavirin combination therapy have been reported in the literature to be causally associated with $\mathrm{AP}^{[47-48]}$. As a consequence of the multifactorial effects, triple combination therapy may lead to an increased risk of AP. Patients receiving PI regimens or the recommended triple combination therapy for the treatment of COVID-19 should be closely observed. Drug-induced AP should be considered, if patients present with clinical signs and symptoms of pancreatitis, including abdominal pain, nausea, vomiting, and conjunction with abnormal levels of serum lipase or/and amylase.

We also assessed and compared the fatality rates of AP associated with Pls to investigate differences in the severity of AP associated with various PIs. It was observed that AP was generally associated with poor outcomes, exhibiting a fatality rate of $14.02 \%$, which was more than two times that found by Riedelet al. in a cohort study that followed 5,970 HIV-infected patients ${ }^{[39]}$. In that study, five patients died of pancreatitis during their hospitalization, yielding an in-hospital mortality rate of $5.9 \%$ for AP. As there is no consensus definition of acute pancreatitis, the different inclusion criteria used in the two studies may have resulted in different specificities and sensitivities of case inclusion. This may have caused the difference between the fatality rates in the two studies. Furthermore, we found that among all 271 reported PI-induced AP cases, compared with the other PIs, ritonavir (18.87\%) and lopinavir/ritonavir (22.73\%) appeared to be associated with a higher risk of death. However, based on the collected data, there was no significant difference in fatality rates across different PI regimens

Page $9 / 13$ 
(Pearson's chi-square test for overall comparison, $p=0.730)$. Fatal events occurred in $1(25.00 \%)$ of 4 patients treated with saquinavir and 1 (20.00\%) of 5 patients treated with nelfinavir; however, there were not enough cases reported to draw a conclusion, and continued surveillance is needed.

Based on spontaneous reporting systems (SRSs), disproportionality analysis and Bayesian analysis allow for signal detection rapidly and generate hypothesis about associations between AP and various PI regimens. However, it should be noted that in addition to many advantages, data mining techniques used in this study still have several limitations. First, affected by the inherent limitation of SRSs, sources of AP reports are non-homogeneous. Incomplete reporting, underreporting, false reporting, and inaccuracy might result in reporting bias and even misleading ${ }^{[49]}$. Second, owing to a lack of insufficient information in the FAERS database, the possibility of verification of the clinical findings justifying the reported AP is quite limited, and it is also scarcely possible to control such confounding factors as indications, pre-existing pancreatic diseases, comorbidities or other factors which might have an impact on AP occurrence ${ }^{[50]}$. Third, as reports extracted from the FAERS database do not reflect the total number of adverse reactions involving AP, the number of reports for a particular PI may be influenced by the extent of use of the product, which may be affected by some factors such as enterprise publicity and product price ${ }^{[49,50]}$. It cannot be used to quantify the incidence of PI-associated AP. Data mining techniques only provide a profile of Pl-associated AP through signal detection. It is generally insufficient to prove the causal relationship, which needs to be replicated ideally by prospective studies ${ }^{[51]}$

\section{Conclusion}

Based on real-world practice data, this pharmacovigilance study identified associations between AP and various PI regimens, including lopinavir/ritonavir, darunavir and nelfinavir, which are potential therapeutics for COVID-19. Indinavir appeared to have a stronger association with AP than other PIs. Moreover, AP associated with ritonavir boosted regimens had an earlier onset and occurred as soon as after the first several doses in some cases. Further pharmacoepidemiological studies should continue to evaluate the hypotheses generated by this study. Our findings provide a foundation for continued surveillance and investigation into this matter.

Not only patients receiving long-term PI treatment, but also those receiving PI regimens for the short -term treatment of COVID-19 should be closely observed.

\section{List Of Abbreviations}

PI: Protease inhibitor

$A P$ : Acute pancreatitis

FAERS: Food and Drug Administration's Adverse Event Reporting System

ADR: Adverse drug reaction

COVID-19: Coronavirus disease 2019

HARRT: Highly active antiretroviral therapy

HIV: Human immunodeficiency virus

SARS-CoV:Severe acute respiratory syndrome coronavirus

MERS-CoV: Middle East respiratory syndrome coronavirus

ROR: Reporting odds ratio

PRR: Proportional reporting ratio

BCPNN: Bayesian confidence propagation neural network

MGPS: Multi-item gamma Poisson shrinke

IQR: Interquartile range

NRTI: Nucleotide reverse-transcriptase inhibitor

NNRTI: Non-nucleoside reverse-transcriptase inhibitor

SRS: Spontaneous reporting system

\section{References}

1. World Health Organization: Coronavirs disease (COVID-2019) situation report-125. https://www.who.int/docs/default-source/coronaviruse/situationreports/20200524-covid-19-sitrep-125.pdf?sfvrsn=80e7d7f0_2. Accessed 25 May 2020.

2. Ghosh AK, Osswald HL, Prato G. Recent Progress in the Development of HIV-1 Protease Inhibitors for the Treatment of HIV/AIDS. Journal of medicinal chemistry. 2016;59(11):5172-208. https://doi.org/10.1021/acs.jmedchem.5b01697

Page $10 / 13$ 
3. Hughes PJ, Cretton-Scott E, Teague A, Wensel TM. Protease Inhibitors for Patients With HIV-1 Infection: A Comparative Overview. P \& T : a peer-reviewed journal for formulary management. 2011;36(6):332-45.

4. Chu CM, Cheng VC, Hung IF, Wong MM, Chan KH, Chan KS, et al. Role of lopinavir/ritonavir in the treatment of SARS: initial virological and clinical findings. Thorax. 2004;59(3):252-6. https://doi.org/10.1136/thorax.2003.012658

5. Sheahan TP, Sims AC, Leist SR, Schafer A, Won J, Brown AJ, et al. Comparative therapeutic efficacy of remdesivir and combination lopinavir, ritonavir, and interferon beta against MERS-CoV. Nature communications. 2020;11(1):222. https://doi.org/10.1038/s41467-019-13940-6

6. Kim UJ, Won EJ, Kee SJ, Jung SI, Jang HC. Combination therapy with lopinavir/ritonavir, ribavirin and interferon-alpha for Middle East respiratory syndrome. Antiviral therapy. 2016;21(5):455-9. https://doi.org/10.3851/imp3002

7. Kim JY, Choe PG, Oh Y, Oh KJ, Kim J, Park SJ, et al. The First Case of 2019 Novel Coronavirus Pneumonia Imported into Korea from Wuhan, China: Implication for Infection Prevention and Control Measures. Journal of Korean medical science. 2020;35(5):e61. https://doi.org/10.3346/jkms.2020.35.e61

8. Lim J, Jeon S, Shin HY, Kim MJ, Seong YM, Lee WJ, et al. Case of the Index Patient Who Caused Tertiary Transmission of COVID-19 Infection in Korea: the Application of Lopinavir/Ritonavir for the Treatment of COVID-19 Infected Pneumonia Monitored by Quantitative RT-PCR. Journal of Korean medical science. 2020;35(6):e79. https://doi.org/10.3346/jkms.2020.35.e79

9. Yamamoto N, Yang R, Yoshinaka Y, Amari S, Nakano T, Cinatl J, et al. HIV protease inhibitor nelfinavir inhibits replication of SARS-associated coronavirus. Biochemical and biophysical research communications. 2004;318(3):719-25. https://doi.org/10.1016/j.bbrc.2004.04.083

10. Chinese Clinical Trial Registry: Index of studies of Novel Coronavirus Pneumonia (COVID-19). http://www.chictr.org.cn/searchproj.aspx?title=covid19\&officialname=\&subjectid=\&secondaryid=\&applier=\&studyleader=\&ethicalcommitteesanction=\&sponsor=\&studyailment=\&studyailmentcode=\&studyty Accessed 24 May 2020.

11. Palella FJ, Jr., Delaney KM, Moorman AC, Loveless MO, Fuhrer J, Satten GA, et al. Declining morbidity and mortality among patients with advanced human immunodeficiency virus infection. HIV Outpatient Study Investigators. The New England journal of medicine. 1998;338(13):853-60. https://doi.org/10.1056/nejm199803263381301

12. Calza L, Manfredi R, Farneti B, Chiodo F. Incidence of hyperlipidaemia in a cohort of 212 HIV-infected patients receiving a protease inhibitor-based antiretroviral therapy. International journal of antimicrobial agents. 2003;22(1):54-9. https://doi.org/10.1016/s0924-8579(03)00100-6

13. Warriner AH, Burkholder GA, Overton ET. HIV-related metabolic comorbidities in the current ART era. Infectious disease clinics of North America. 2014;28(3):457-76. https://doi.org/10.1016/j.idc.2014.05.003

14. Montessori V, Press N, Harris M, Akagi L, Montaner JS. Adverse effects of antiretroviral therapy for HIV infection. CMAJ : Canadian Medical Association journal = journal de l'Association medicale canadienne. 2004;170(2):229-38.

15. Safrin S, Grunfeld C. Fat distribution and metabolic changes in patients with HIV infection. AIDS (London, England). 1999;13(18):2493-505. https://doi.org/10.1097/00002030-199912240-00002

16. Oliveira NM, Ferreira FA, Yonamine RY, Chehter EZ. Antiretroviral drugs and acute pancreatitis in HIV/AIDS patients: is there any association? A literature review. Einstein (Sao Paulo, Brazil). 2014;12(1):112-9. https://doi.org/10.1590/s1679-45082014rw2561

17. Croxtall JD, Perry CM. Lopinavir/Ritonavir: a review of its use in the management of HIV-1 infection. Drugs. 2010;70(14):1885-915. https://doi.org/10.2165/11204950-000000000-00000

18. Abbott Laboratories: Kaletra (lopinavir/ritonavir) tablets and oral solution. Prescribing information. http://www.kaletra.com. Accessed 24 May 2020.

19. Reisler RB, Murphy RL, Redfield RR, Parker RA. Incidence of pancreatitis in HIV-1-infected individuals enrolled in 20 adult AIDS clinical trials group studies: lessons learned. Journal of acquired immune deficiency syndromes (1999). 2005;39(2):159-66.

20. Bush ZM, Kosmiski LA. Acute pancreatitis in HIV-infected patients: are etiologies changing since the introduction of protease inhibitor therapy? Pancreas. 2003;27(1):e1-5. https://doi.org/10.1097/00006676-200307000-00016

21. Manfredi R, Calza L, Chiodo F. A case-control study of HIV-associated pancreatic abnormalities during HAART era. Focus on emerging risk factors and specific management. European journal of medical research. 2004;9(12):537-44.

22. Manfredi R, Calza L. HIV infection and the pancreas: risk factors and potential management guidelines. International journal of STD \& AIDS. 2008;19(2):99-105. https://doi.org/10.1258/ijsa.2007.007076

23. Mirete G, Masia M, Gutierrez F, Mora A, Escolano C, Maestre A. Acute pancreatitis as a complication of ritonavir therapy in a patient with AIDS. European journal of clinical microbiology \& infectious diseases : official publication of the European Society of Clinical Microbiology. 1998 Nov;17(11):810-1. https://doi.org/10.1007/s100960050194

24. Perry RC, Cushing HE, Deeg MA, Prince MJ. Ritonavir, triglycerides, and pancreatitis. Clinical infectious diseases : an official publication of the Infectious Diseases Society of America. 1999;28(1):161-2. https://doi.org/10.1086/517194

25. Di Martino V, Ezenfis J, Benhamou Y, Bernard B, Opolon P, Bricaire F, et al. Severe acute pancreatitis related to the use of nelfinavir in HIV infection: report of a case with positive rechallenge. AIDS (London, England). 1999;13(11):1421-3. https://doi.org/10.1097/00002030-199907300-00028

26. Van Puijenbroek EP, Bate A, Leufkens HG, Lindquist M, Orre R, Egberts AC. A comparison of measures of disproportionality for signal detection in spontaneous reporting systems for adverse drug reactions. Pharmacoepidemiology and drug safety. 2002;11(1):3-10. https://doi.org/10.1002/pds.668

27. Szumilas M. Explaining odds ratios. Journal of the Canadian Academy of Child and Adolescent Psychiatry = Journal de l'Academie canadienne de psychiatrie de l'enfant et de l'adolescent. 2010;19(3):227-9.

28. Ooba N, Kubota K. Selected control events and reporting odds ratio in signal detection methodology. Pharmacoepidemiology and drug safety. 2010;19(11):1159-65. https://doi.org/10.1002/pds.2014

Page $11 / 13$ 
29. Evans SJ, Waller PC, Davis S. Use of proportional reporting ratios (PRRs) for signal generation from spontaneous adverse drug reaction reports. Pharmacoepidemiology and drug safety. 2001;10(6):483-6. https://doi.org/10.1002/pds.677

30. Hauben M, Madigan D, Gerrits CM, Walsh L, Van Puijenbroek EP. The role of data mining in pharmacovigilance. Expert opinion on drug safety. 2005;4(5):929-48. https://doi.org/10.1517/14740338.4.5.929

31. Norén GN, Bate A, Orre R, Edwards IR. Extending the methods used to screen the WHO drug safety database towards analysis of complex associations and improved accuracy for rare events. Statistics in medicine. 2006;25(21):3740-57. https://doi.org/10.1002/sim.2473

32. Hauben M. A brief primer on automated signal detection. The Annals of pharmacotherapy. 2003;37(7-8):1117-23. https://doi.org/10.1345/aph.1C515

33. Louis TA, Shen W. [Bayesian Data Mining in Large Frequency Tables, with an Application to the FDA Spontaneous Reporting System]: Discussion. American Statistician. 1999;53(3):196.

34. Szarfman A, Machado SG, O'Neill RT. Use of screening algorithms and computer systems to efficiently signal higher-than-expected combinations of drugs and events in the US FDA's spontaneous reports database. Drug safety. 2002;25(6):381-92. https://doi.org/10.2165/00002018-200225060-00001

35. Moore RD, Keruly JC, Chaisson RE. Incidence of pancreatitis in HIV-infected patients receiving nucleoside reverse transcriptase inhibitor drugs. AIDS (London, England). 2001;15(5):617-20. https://doi.org/10.1097/00002030-200103300-00011

36. Dragovic G, Milic N, Jevtovic DJ. Incidence of acute pancreatitis and nucleoside reverse transcriptase inhibitors usage. International journal of STD \& AIDS. 2005;16(6):427-9. https://doi.org/10.1258/0956462054094042

37. Centers for Disease Control and Prevention: HIV Surveillance Report: Estimated HIV Incidence and Prevalence in the United States 2010-2016; vol 24. https://www.cdc.gov/hiv/pdf/library/reports/surveillance/cdc-hiv-surveillance-supplemental-report-vol-24-1.pdf. Accessed 24 May 2020.

38. Guo JJ, Jang R, Louder A, Cluxton RJ. Acute pancreatitis associated with different combination therapies in patients infected with human immunodeficiency virus. Pharmacotherapy. 2005;25(8):1044-54. https://doi.org/10.1592/phco.2005.25.8.1044

39. Riedel DJ, Gebo KA, Moore RD, Lucas GM. A ten-year analysis of the incidence and risk factors for acute pancreatitis requiring hospitalization in an urban HIV clinical cohort. AIDS patient care and STDs. 2008;22(2):113-21. https://doi.org/10.1089/apc.2007.0034

40. Friedewald VE, Ballantyne CM, Bays HE, Jones PH. The editor's roundtable: hypertriglyceridemia. The American journal of cardiology. 2013;112(8):113341. https://doi.org/10.1016/j.amjcard.2013.07.033

41. Lederle FA, Bloomfield HE. Drug treatment of asymptomatic hypertriglyceridemia to prevent pancreatitis: where is the evidence? Annals of internal medicine. 2012;157(9):662-4. https://doi.org/10.7326/0003-4819-157-9-201211060-00011

42. Sun HY, Chang SY, Sheng WH, Chen MY, Hsieh SM, Tseng YT, et al. Incidence of acute pancreatitis in human immunodeficiency virus-positive patients with hypertriglyceridemia: is it really high? Pancreas. 2012;41(2):283-9. https://doi.org/10.1097/MPA.0b013e3182267fc0

43. Marot JC, Jonckheere S, Munyentwali H, Belkhir L, Vandercam B, Yombi JC. Tigecycline-induced acute pancreatitis: about two cases and review of the literature. Acta clinica Belgica. 2012;67(3):229-32. https://doi.org/10.2143/acb.67.3.2062663

44. Tsiodras S, Mantzoros C, Hammer S, Samore M. Effects of protease inhibitors on hyperglycemia, hyperlipidemia, and lipodystrophy: a 5-year cohort study. Archives of internal medicine. 2000;160(13):2050-6. https://doi.org/10.1001/archinte.160.13.2050

45. Salami AK, Akande AA, Olokoba AB. Serum lipids and glucose abnormalities in HIV/AIDS patients on antiretroviral therapies. West African journal of medicine. 2009;28(1):10-5. https://doi.org/10.4314/wajm.v28i1.48417

46. Lugassy DM, Farmer BM, Nelson LS. Metabolic and hepatobiliary side effects of antiretroviral therapy (ART). Emergency medicine clinics of North America. 2010;28(2):409-19. https://doi.org/10.1016/j.emc.2010.01.011

47. Balani AR, Grendell JH. Drug-induced pancreatitis : incidence, management and prevention. Drug safety. 2008;31(10):823-37. https://doi.org/10.2165/00002018-200831100-00002

48. Nitsche C, Maertin S, Scheiber J, Ritter CA, Lerch MM, Mayerle J. Drug-induced pancreatitis. Current gastroenterology reports. 2012;14(2):131-8. https://doi.org/10.1007/s11894-012-0245-9

49. Golomb, B.A., Verden, A., Messner, A.K. et al. Amyotrophic Lateral Sclerosis Associated with Statin Use: A Disproportionality Analysis of the FDA's Adverse Event Reporting System. Drug Saf. 2018;41(4), 403-413. https://doi.org/10.1007/s40264-017-0620-4

50. Shen J, Yang J, Zhao B. A Survey of the FDA's Adverse Event Reporting System Database Concerning Urogenital Tract Infections and Sodium Glucose Cotransporter-2 Inhibitor Use. Diabetes Ther. 2019;10(3):1043-1050. https://doi.org/10.1007/s13300-019-0611-9

51. Fan Q, Hu Y, Yang C, Zhao B. Myocarditis following the use of different immune checkpoint inhibitor regimens: A real-world analysis of post-marketing surveillance data. Int Immunopharmacol. 2019;76:105866. https://doi.org/10.1016/j.intimp.2019.105866

\section{Figures}




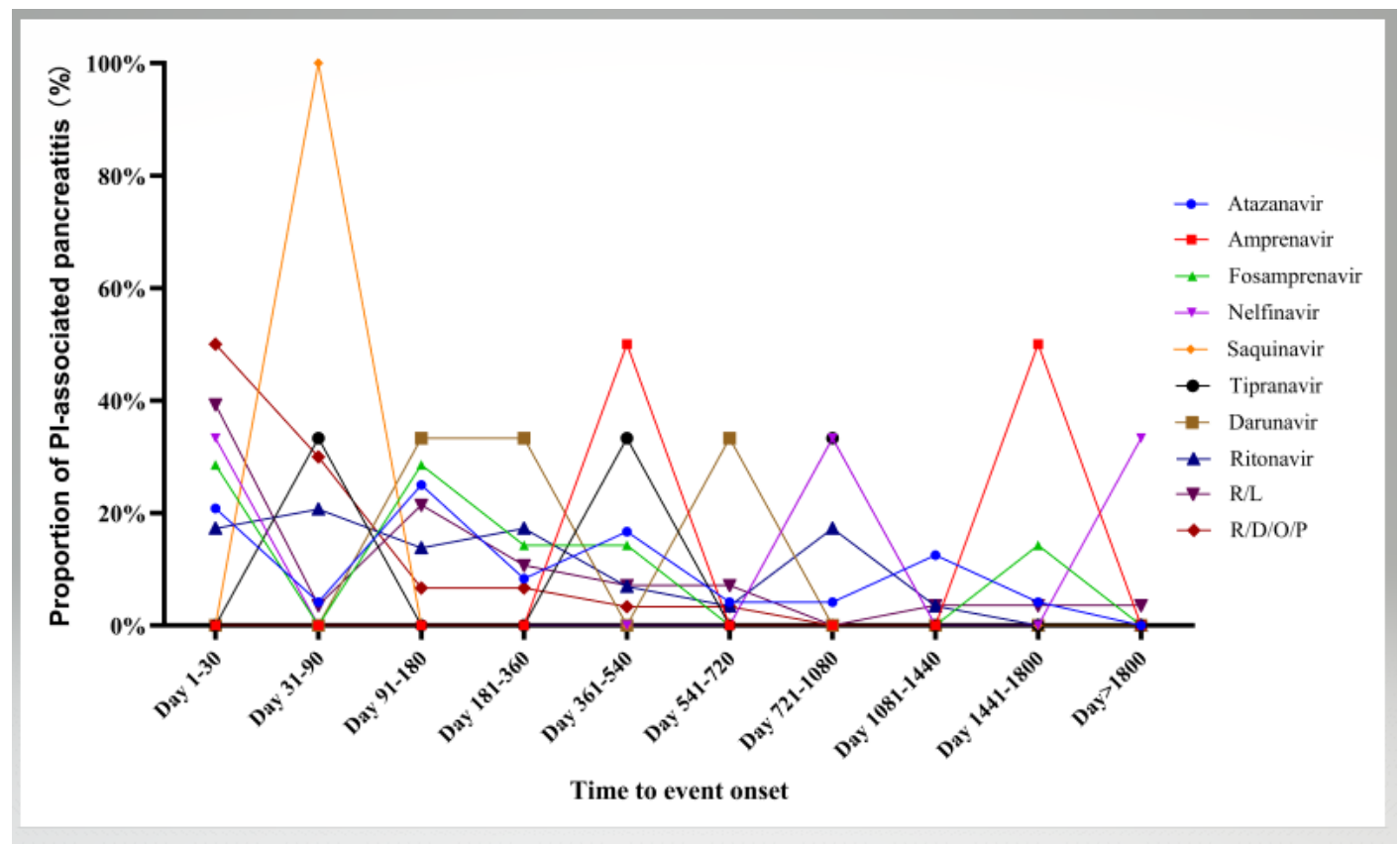

Figure 1

Time to onset of acute pancreatitis associated with different protease inhibitor regimens (Pearson's chi-square test, $\mathrm{P}=0.0048$ ) 